\title{
Las representaciones historiográficas postmodernas: Maus y la novela gráfica sobre el Holocausto*
}

\section{Postmodern Historiographic Representations: Maus and the Graphic Novel on the Holocaust}

\author{
Aitor Bolaños de Miguel \\ Universidad Internacional de La Rioja (UNIR) \\ ambdem5@gmail.com
}

\section{Resumen}

Este artículo examina la forma en la que la novela gráfica Maus ha plasmado las múltiples dimensiones y problemáticas que nos encontramos al intentar representar un acontecimiento límite como el Holocausto. Para ello, se presentan unas palabras previas sobre las posibilidades del cómic para representar el pasado. A continuación, se analizan los principales recursos de la obra de Art Spiegelman para representar la Shoah para terminar con unas reflexiones finales sobre la capacidad de los llamados experimentos historiográficos postmodernos para dar cuenta del sufrimiento y de las experiencias vividas por las víctimas, y por sus legatarios, en relación con fenómenos como la Solución final.

\section{Palabras clave}

Holocausto, sufrimiento, Maus, experimientos historiográficos postmodernos, Novela gráfica.

\begin{abstract}
This article examines the way in which the graphic novel Maus has represented the multiple dimensions and problems we encounter when representing a limit-event such as the Holocaust. To this purpose, some previous words on the possibilities of the comic to represent the past are needed. Then, we analyze the main resources of Art Spiegelman's work to represent the Shoah, by ending with some final reflections on the ability of the so-called postmodern historiographic experiments to narrate the suffering and experiences lived by the victims and their legatees, in relation to phenomena such as the Final Solution.
\end{abstract}

\section{Keywords}

Holocaust, suffering, Maus, postmodern historiographic experiments, graphic novel. 


\section{"An engine, an engine \\ Chuffing me off like a Jew A Jew to Dachau, Auschwitz, Belsen. I think I may will be a Jew" Sylvia Plath ("Daddy", 1965)}

"How we "picture" social suffering becomes that experience, for the observers and even for the sufferers/perpetrators. What we represent and how we represent it prefigure what we will, or will not, do to intervene". ${ }^{1}$

\section{Introducción. El Holocausto y la atracción del abismo}

Como cualquier otro suceso del pasado, el Holocausto no es un acontecimiento histórico "fijado en ámbar", por utilizar una expresión de La Capra. Por el contrario, es un "acontecimiento histórico límite", que ejerce un amplísimo poder de atracción en muy diversos ámbitos y disciplinas. Por ejemplo, en los diversos intentos (testimoniales, literarios, sociológicos, cinematográficos, teatrales, poéticos, etc.) de comprenderlo, representarlo y darle sentido. En todo caso, y al margen de la singularidad del Holocausto o, incluso, al margen de su sacralización contemporánea, las posiciones sobre nuestra capacidad para representar el Holocausto (o la Shoah) se han venido manteniendo entre dos extremos clásicos: aquel que afirma que se puede representar (postura que mantienen historiadores como Vidal-Naquet, White o Todorov o supervivientes como Levi o Agamben) y el que lo niega (como Wajcman). Y, dentro de éstos, los que lo hacen en sentido absoluto y los que lo hacen en sentido relativo, referida a alguno de sus aspectos (como Wiesel o Jankelevitch, respectivamente).

Pues bien, se pueda conocer o representar adecuada y completamente, el Holocausto es uno de los acontecimientos fundacionales en la construcción de la identidad judía de los últimos 60-70 años. De hecho, desde los años ochenta, el Holocausto se ha convertido en el acontecimiento central de la historia del pueblo judío, en general, y del propio Estado de Israel en Palestina, en particular. ${ }^{2}$ Pero el Holocausto es, también, un acontecimiento histórico fundacional para Occidente, para la interpretación del siglo XX en su conjunto y, por tanto, para la reelaboración de nuestra identidad tras los traumas colectivos de la $2^{\mathrm{a}}$ G.M. y del genocidio nazi. Y ello porque, en primer lugar, muchas de las representaciones del Holocausto se han adherido a lo que Allison Landsberg ha llamado "prosthetic memory", que no son más que memorias colectivas compartidas por quienes no han vivido un acontecimiento pero comparten "representaciones historiográficas comunes". ${ }^{3} \mathrm{Y}$, también, porque, entre, entre otras

\footnotetext{
*Este artículo se inserta en el Proyecto de I+D "Sufrimiento social y condición de víctima: dimensiones epistémicas, sociales, políticas y estéticas” (FFI2015-69733-P), financiado por el Programa Estatal de Fomento de la Investigación Científica y Técnica de Excelencia. Agradezco a los profesores Reyes Mate y Robert Rosenstone su ayuda y magisterio para la elaboración de este trabajo académico.

1 Arthur Kleinam, Veena Das y Margaret Lock, Social Suffering (Berkeley y London: University of California Press, 1997), xii y xiii.

2 Julia Resnik, "'Sites of memory' of the Holocaust: shaping national memory in the education system in Israel", Nations and Nationalism, 9, 2 (2003): 293-313.

${ }^{3}$ Alison Landsberg, Prosthetic Memory: The Transformation of American Remembrance in the Age of Mass Culture (New York: Columbia University Press, 2004).
} 
consecuencias, el Holocausto nos alerta de que, indiscutiblemente, hay ciertos traumas históricos y ciertas heridas individuales que no curan ni se cierran sin dejar "cicatrices o residuos en el presente". ${ }^{4}$ Cicatrices que son memorias traumáticas de las experiencias sufridas por las víctimas, por los supervivientes y por sus familiares y conciudadanos.

Desde este punto de vista, ¿cuál es la forma adecuada de elaborar y de representar, convenientemente, dichas memorias, dichas experiencias? Si se quiere representar el ascenso del nazismo, la construcción del Tercer Reich o el desarrollo de la Segunda Guerra Mundial, se puede elegir un esquema narrativo clásico, con su comienzo, su nudo y su desenlace: el fin de la guerra, los Juicios de Nuremberg y la reconstrucción de posguerra. Pero ¿cómo se representa, qué esquema cronológico es el apropiado para dar cuenta de las experiencias vividas por las víctimas de los campos de concentración y de exterminio? ¿Y cómo representar adecuadamente el sufrimiento, pasado y presente, de las víctimas y de los supervivientes del Holocausto, que sufren de estrés post-traumático y viven, en el presente, sufriendo continuas experiencias de memorias invasivas o de recuerdos lesivos? O, como se pregunta Adam Zagajewski, ¿forma parte el Holocausto de un mundo no representado, siguiendo la sugerencia de Freud en el sentido de que el trauma es lo que queda fuera de nuestras representaciones $?^{5}$ Aunque hay varios libros, como el de Laurence Rees, que intentan dar cuenta del Holocausto desde un punto de vista cronológico, las experiencias y el sufrimiento vivido por las víctimas y por los supervivientes de la Shoah requieren de estrategias más sofisticadas, puesto que las experiencias vividas en los campos de concentración y de exterminio producen una dinámica en la que el pasado y el presente se mezclan de una forma lesiva, imprevisible y perversa.

Los estudios sobre el Holocausto se insertan en una dinámica que tiene dos cabezas: la de la relación entre la historia y la memoria, por un lado, y la de los problemas de la representación del pasado, especialmente en casos de acontecimientos límite (traumáticos y/o traumas colectivos), por el otro. Berel Lang ha subrayado el hecho de que el Holocausto, como fenómeno histórico, se encuentra entre la historiografía y la memoria, especialmente en el seno de una cultura memorística como la judía. ${ }^{6}$ Alon Confino ha precisado que esta dinámica bicéfala se encuentra bastante separada: por un lado, están los teóricos y los estudiosos del Holocausto y, por el otro, los historiadores "tradicionales". A los que hay que añadir los testimonios de las víctimas y de los supervivientes, basadas en los recuerdos de sus experiencias y de su sufrimiento. Es decir, representar el Holocausto requiere tanto una auditoría imparcial de todas las pruebas disponibles (perspectiva del historiador) como una profunda simpatía por el recuerdo del sufrimiento de las víctimas (perspectiva de las víctimas): tanto la (supuesta) asepsia del historiador como la (descarnada) implicación de las víctimas. O lo que es lo mismo: una rigurosa descripción del acontecimiento y una representación emotiva, no neutral y no indiferente respecto de sus terribles consecuencias.

\footnotetext{
${ }^{4}$ Dominick LaCapra, Escribir la historia, escribir el trauma (Buenas Aires: Nueva Visión, 2005), 157.

${ }^{5}$ Adam Zagajewski, Solidaridad y soledad (Barcelona: Acantilado, 2010), 10.

${ }^{6}$ Berel Lang, The Future of the Holocaust: Between History and Memory (Ithaca: Cornell University Press, 1999).

7 Alon Confino, "Narrative Form and Historical Sensation: On Saul Friedlander's The Years of Extermination", History and Theory 48, 3 (2009): 199-219, 207.
} 


\section{El cómic y las representaciones postmodernas sobre el pasado}

Si nos centramos en las representaciones sobre el Holocausto, podremos observar que tanto la historia profesional como el arte (la literatura, el cine, la televisión, la pintura, el teatro, la escultura, el cómic, los monumentos), ${ }^{8}$ tanto el testimonio de los supervivientes (estoy pensando en Ana Frank, Primo Levi o en los supervivientes que aparecen en Shoah de Lanzmann) como diversas mezclas de testimonio y creación artística, ${ }^{9}$ han realizado esfuerzos muy divergentes para comprender y dar significado a dicho acontecimiento. Así, la historiografía no ha sido la única encargada de representar el Holocausto. Precisamente, aunque el Holocausto haya propiciado más investigación y escritura historiográfica que cualquier otro acontecimiento de la historia judía, su imagen ha sido forjada en el "crisol del novelista" más que en el "yunque del historiador". 10 Es decir, las representaciones artísticas (especialmente las literarias y las fílmicas) tienen una enorme importancia en nuestra percepción y en nuestra comprensión del Holocausto. El acceso al pasado se ha transformado en un asunto visual, más que lingüístico. En todo caso, en un asunto audio-visual. En la actualidad, siguiendo a Rosenstone, "la gran fuente de conocimiento histórico de la mayoría de la población (fuera del despreciado libro de texto) seguramente es el medio visual, un conjunto de instituciones cuyo control está casi completamente fuera del alcance de aquellos de nosotros que dedicamos nuestras vidas a la historia" ". Es esta una de las razones por la que surge nuestro interés por el cine: porque es un medio muy popular a través del cual muchas personas se informan sobre el pasado. Pero, también, porque es muy interesante estudiar las posibilidades y los límites de los medios audio-visuales para dar cuenta del pasado, particularmente de eventos como el Holocausto. Y, en los últimos años, en las últimas décadas, también podemos hablar del cómic o de la novela gráfica, como un medio válido para representar el Holocausto, y, sobre todo, para divulgar el significado del acontecimiento entre las generaciones más jóvenes (junto con los videojuegos y los blogs colectivos de historia, por ejemplo). Al lado de los debates sobre la representabilidad del Holocausto; al lado de la discusiones sobre la pertinencia moral de representar explícitamente la Shoah; aparecen, continuamente, distintas representaciones audio-visuales. Es decir: imágenes pese a todo, por utilizar la compleja y pertinente expresión de Didi-Huberman.

\footnotetext{
${ }^{8}$ Lillian Kremer (ed.), Holocaust Literature: Agosín to Lentin (New York y London: Routledge, 2003). Sobre la representación televisiva del pasado, en general, vid. Daniel Dayan y Elihu Katz, Media Events: The Live Broadcasting of History (Cambridge: Harvard University Press, 1994). Sobre la representación televisiva del Holocausto, vid. Tony Barta, "Film Nazis: The Great Escape", en Barta, (ed.), Screening the Past: Film and the Representation of History (Westport: Preager, 1998), 139 y ss. Gene A. Plunka, Holocaust Drama. The Theater of Atrocity (Cambridge y New York: Cambridge University Press, 2009). y Andreas Huyssen, "La política de la identificación: 'Holocausto' y el drama en Alemania Occidental”, en Huyssen, Después de la Gran División. Modernismo, cultura de masas y posmodernismo (Buenos Aires: Adriana Hidalgo, 2002), 170-203, 179 y ss; Jay Winter, Sites of Memory, Sites of Mourning: The Great War in European Cultural History (Cambridge: Cambridge University Press, 1995); Paul Carrier, Holocaust Monuments and National Memory Cultures in France and Germany Since 1989 (New York: Berghahn Books, 2005).

9 Cathy Caruth, Trauma: Explorations in Memory (Baltimore: The Johns Hopkins University Press, 1995), 16.

${ }^{10}$ Yosef H. Yerushalmi, Zajor: La Historia Judía y la Memoria Judía (Barcelona: Anthropos, 2006), 117.

${ }^{11}$ Rosenstone, R.A., "La historia en imágenes/la historia en palabras: reflexiones sobre la posibilidad real de llevar la historia a la pantalla", Istor, V, 20 (2005): 91-108, 93.
} 
Como afirma Huyssen, "una vez que reconocemos la brecha constitutiva que media entre la realidad y su representación en el lenguaje o en la imagen, tenemos que estar abiertos hacia las diferentes posibilidades de representar lo real [pasado] y sus memorias". ${ }^{12}$ Y es que el arte es emoción y de lo que se trata a la hora de enfrentarnos al Holocausto es de la experiencia y de la emoción: del sufrimiento de millones de seres humanos. Como decía Zagajewski, "las tragedias personales son mudas, el drama colectivo es locuaz". ${ }^{3}$ Es decir, hay que reconocer la importancia de las representaciones artísticas (especialmente las literarias y visuales) en nuestra percepción y en nuestra comprensión del Holocausto. Y ello por la sencilla razón de que pocos ciudadanos Occidentales han leído las obras de Friedlander, Hillberg o Goldhagen. Por otro lado, existe una saturación de representaciones sobre el Holocausto (incluso lo que se ha llamado una "industria" sobre la Shoah), qué duda cabe, como casi sobre cualquier acontecimiento del pasado, pero son las representaciones audio-visuales las que parecen calar más en distintas capas y sectores de la población actual.

Así, el pasado no tiene por qué ser representado únicamente en papel, a través de una monografía o un manual de historia, sino que existen otras formas de describirlo, explicarlo e interpretarlo. Unas formas que utilizan, además de la palabra escrita, el sonido, las imágenes, los testimonios orales, el montaje, la música, etc. Entre estas formas, ocupan una posición destacable tanto el cómic como el cine, que son los dos canales más populares en la representación contemporánea del pasado, junto con la televisión (telefilms, documentales y series), los videojuegos, las revistas de divulgación y las webs historiográficas colaborativas. Así, podemos encontrar cómics que se ofrecen representaciones del pasado: desde Maus, de Art Spiegelman, a Louis Riel: A Comic Strip Biography, de Chester Brown, o Yo, René Tardi. Prisionero de Guerra en Stalag II, de Jacques Tardi, pasando por The Search, de Eric Heuvel, Ruud van der Rol y Lies Schippers, La Gran Guerra, de Joe Sacco o Los surcos del azar, de Paco Plaza.

Sin embargo, aunque se ha reconocido al cómic o a la novela gráfica como expresiones artísticas (de hecho, forman parte del llamado "noveno arte"), no se han considerado todavía, suficientemente, su naturaleza, sus posibilidades y sus límites para representar el pasado. Siguiendo a Witek, es una premisa de este artículo que el cómic, como narración historiográfica y como producto cultural, es merecedor de un análisis crítico cultural serio, debido a que se han vuelto cada vez más complejo y sofisticado. ${ }^{14}$ Por otro lado, además del consumo comercial de "historietas" (por usar el término en castellano), el uso de los cómics o de las novelas gráficas en las aulas, por ejemplo, puede ayudar a conseguir varios objetivos. En primer lugar, proporcionan conocimiento sobre periodos del pasado, además del libro de texto. Es decir, los cómics son artefactos atractivos y novedosos para adquirir información. En segundo lugar, ese conocimiento, al ser proporcionado mediante ilustraciones, dibujos y diseños, facilitan su asimilación por parte de un público que cada vez es más reacio a leer. En tercer lugar, mejora las competencias de los alumnos en la interpretación y comprensión de las fuentes visuales presentes en la sociedad. En cuarto lugar, el contenido, la forma de narrar o el estilo de un cómic puede ser utilizado como una buena excusa para plantear debates en clase, o para profundizar en contenidos propuestos en el curriculum oficial. En quinto lugar, los estudiantes también pueden elaborar sus propias representaciones gráfico-visuales para

\footnotetext{
12 Andreas Huyssen, "En busca del tiempo futuro", Puentes, 1, 2 (2000): 10.

${ }^{13}$ Zagajewski, A. Solidaridad y soledad, 135.

${ }^{14}$ Joseph Witek, Comic Books as History. The Narrative of Jack Jackson, Art Spiegelman, and Harvey Pekar (Jackson: University Press Of Mississippi, 1989), 3 y 8.
} 
mejorar y desarrollar sus distintas competencias, aptitudes, contenidos y valores. Y, finalmente, las narraciones visuales pueden mejorar el desarrollo de competencias curriculares de orden social y ciudadanas. Así, el cómic contribuye al alfabetismo y al desarrollo de las habilidades de lectoescritura entre los estudiantes jóvenes, estimula el gusto por la lectura y el interés por interpretar críticamente el pasado reciente.

Por todo ello, el uso del comic book o de la novela gráfica, como se dice desde hace un par de décadas (aunque el término se remonta a 1964, a un ensayo de Richard Kyle), puede ayudar a transmitir una serie de conocimientos sobre el pasado reciente, puede "bring to bear on history", como ha escrito Richard Iadonisi, ${ }^{15} \mathrm{y}$, puede, además, desarrollar las capacidades emotivas de los lectores, como hace el cine (y muchas veces no consigue el libro académico de historia). Karin Kukkonen, analizando Maus con las herramientas conceptuales de Hayden White, subraya que el pasado no es solo una materia interesante para las personas que nos precedieron sino, fundamentalmente, para los que les hemos sucedido. ${ }^{16}$ Es evidente que el comic book es un arte secuencial, es un arte narrativo (no como muchos de los libros de historia, que son más analíticos o descriptivos que narrativos) y es un arte visual, pero eso no quiere decir que no aporte información verídica sobre el pasado (es decir, "datos históricos", evidencias fácticas o pruebas historiográficas). Al contrario, muchas novelas gráficas se basan en una labor de investigación historiográfica y bibliográfica envidiable, como en Los Tejanos o en Comanche Moon de Jack Jackson, por ejemplo. Por otro lado, la subjetividad del historiador y del novelista gráfico está presente en ambas formas de representar el pasado pero, como han subrayado Chapman, Ellin y Sherif, "the form of subjectivity inherent in comics is rather different from other cultural forms [as history books], basad as it is on the combination of words and images, itself touching on conceptual binaries (or relativisms) of language/art and realism/symbolism". ${ }^{17}$

En las últimas décadas, el Holocausto se ha introducido en las escuelas, como materia de estudio en los sistemas educativos curriculares contemporáneos, tanto en España como en otros países de la Unión Europea, EE.UU., Canadá, Argentina, etc. ${ }^{18}$ Para ello, se está introduciendo el cine, el documental y el cómic en las aulas, como un material privilegiado para transmitir la información sobre tal acontecimiento así como para conseguir que los estudiantes de la educación obligatoria, entre los 6 y los 16 años, conozcan lo sucedido, desarrollen una empatía a favor de las víctimas y una serie de valores contra cualquier forma de discriminación, de violencia política o de genocidio. ${ }^{19}$ Así, por ejemplo, en Berlín, en el Humboldt Gymnasium, una escuela local, se ha introducido un nuevo manual para la enseñanza de la historia, un comic book sobre el Holocausto (dibujado con el estilo denominado de "línea clara", como Tintín), llamado

\footnotetext{
15 Richard Iadonisi (ed.), Graphic History: Essays on Graphic Novels and/as History (Newcastle upon Tyne: Cambridge Scholars Publishing, 2012), 2.

${ }^{16}$ Karin Kukkonen, Studying Comics and Graphic Novels (Chichester: John Wiley \& Sons, 2013), 66.

17 Jane L. Chapman, Adam Sherif y Dan Ellin, Comics, the Holocaust and Hiroshima (Basingstoke y New York: Palgrave, 2015), 7.

18 Vid. http://cbldf.org/2016/05/using-graphic-novels-in-education-teaching-the-holocaust-with-comics/ (19-02-2018); Carrier, P., Fuchs, E. y Messinger, T., The International status of education about the Holocaust: a global mapping of textbooks and curricula. UNESCO/Georg Eckert Institute for International Textbook Research, 2015; y Kumaraswamy, P.R. (Ed.) "Special Issue: Holocaust Education", Contemporary Reviewof the Middle East, 3, 3 (2016). (http://journals.sagepub.com/toc/cmea/3/3, 20-10-2018).

19 Vid. Berenguel Aguilera, I., "Las TIC's y las viñetas. Una propuesta didáctica sobre los totalitarismos a través del cómic Maus". Espiral. Cuadernos del profesorado, 8 (2011): 42-57
} 
The Search, cuyos autores son Eric Hauvel, Rurd van der Rol y Lies Schippers y que ha sido realizado con la colaboración de Anne Frank House en cooperación con el Jewish Historical Musem of Amsterdam. ${ }^{20}$

La idea es que el cómic (así como el resto de medios visuales y gráficos como el cine o el documental) puede usarse para representar y para transmitir representaciones sobre el pasado, basadas en la misma metodología de búsqueda y análisis de fuentes que el tradicional libro de historia, pero usando un medio más actual y más cercano a las nuevas generaciones (el "pictorial fiction", en terminología de Vitek), ${ }^{21}$ con un mayor compromiso por parte del autor en relación con el sufrimiento ocurrido en el pasado y con la intención de emocionar al espectador para que desarrollo su capacidad de empatía (incluso su compasión) y para que realice una labor de desentrañamiento crítico del significado de los hechos del pasado, lo cual estimula un lector más activo.

\section{La novela gráfica Maus, de Art Spiegelman}

Como muestra representativa de esta voluntad por comprender el trauma producido por Auschwitz, vamos a comentar la obra de Art Spiegelman. Para empezar, conviene subrayar que Maus (1986-1991) es un auténtico experimento historiográfico postmoderno sobre la persistencia del pasado en el presente y sobre el carácter abierto y presentista de los trabajos de la memoria, ${ }^{22}$ por un lado. Por el otro, es una obra que intenta hacer frente a la experiencia del Holocausto, así como a la elaboración de su memoria, incluidos los traumas que produjo. ${ }^{23}$ La pregunta que intenta contestar Maus es si se puede "dibujar" el horror, si se puede representar en viñetas la aniquilación de seres humanos así como el sufrimiento de las víctimas y de los supervivientes. Pero, también, y esto es casi más importante, ¿cómo se puede vivir cuando uno ha experimentado, cuando uno ha sufrido el Holocausto? ¿Y cuando su recuerdo forma parte de la experiencia vital de los supervivientes pero, también, de sus familias? De hecho, como ha señalado Babic, Maus "presents itself as a historical narrative set whithin a autobiographical style". ${ }^{24}$

En un primer plano narrativo, en lo que White llama "su contenido manifiesto", Maus describe la investigación que emprende el hijo de un superviviente para comprender la experiencia de sus padres en los campos de concentración. ${ }^{25}$ Para ello, Spiegelman desarrolla una mise-en-scène mixta (gráfica y textual), de naturaleza metaficcional, aprovechando las convenciones pero también las posibilidades narrativas de un medio visual como el cómic. ${ }^{26}$ Así, la apuesta de Maus es representar una tragedia

\footnotetext{
${ }^{20}$ Eric Hauvel, Rurd van der Rol y Lies Schippers, The Search (New York: Farrar Straus Giroux, 2009). Por cierto, existe un film también titulado The Search ( Los Ángeles perdidos, 1948), de Fred Zinnemann, sobre el destino de los niños que sobrevivieron a los campos de concentración y de exterminio.

21 Joseph Witek, Comic Books as History, 6.

${ }^{22}$ Hillary Chute, ""The Shadow of a Past Time": History and Graphic Representation in Maus", Twentieth-Century Literature, 52, 2 (2006): 199-230, 200 y 215.

23 Silvana Vetö, "El Holocausto como acontecimiento traumático. Acerca de la incorporación del concepto freudiano de trauma en la historiografía del Holocausto", Revista de Psicología de la Universidad de Chile, 20, no. 1 (2011): 127-152.

24 Annessa Ann Babic (ed.), Comics as History. Comics as Literature: Roles of the Comic Book in Scholarship, Society, and Entertainment (Madison: Fairleigh Dickinson University Press, 2014), 5.

${ }^{25}$ Joseph Witek, Art Spiegelman: Conversations (Mississippi: The University Press of Mississippi, 2007).

${ }^{26}$ Sobre las posibilidades narrativas del cómic, vid. Jeanne Ewert, “Art Spiegelman's Maus and the Graphic Narrative", en Marie-L. Ryan (ed.), Narrative Across Media. The Languages of Storytelling (Lincoln: University of Nebraska Press, 2004), 178-193.
} 
histórica, de terribles consecuencias y connotaciones personales y sociales, con los medios narrativos, gráficos y textuales del cómic: es decir, usando un "arte secuencial". ${ }^{27}$ Pero Maus es algo más porque, entre otras razones, se centra, precisamente, en el complejo y conmovedor esfuerzo del hijo de un superviviente de Auschwitz por comprender y por relatar el testimonio de un horror que, durante años, ha estado escuchando (muchas veces silenciosamente) de boca de su propio padre. ${ }^{28} \mathrm{Y}$, como ha expresado perfectamente LaCapra, "los testimonios sirven para complementar fuentes documentales de tipo más convencional", aportando a la "verdad" documental, la "autenticidad" de la experiencia personal. ${ }^{29}$ Es decir, mezclar "historia pública" con "historia privada", hechos con experiencias. Tal y como han intentado hacer otras obras gráfico-textuales, como Michel Kichka y su autobiografía Second Generation: The things I didn't tell my father (2016). En esta obra, Kichka considera que la Shoah es un asunto privado y personal pero que pertenece a la Humanidad entera, no a un grupo en particular. Los campos de concentración son enormes cementerios donde, dice el autor, se remueven las cenizas de toda la civilización Occidental. Como Fui hija de supervivientes del Holocausto, de Bernice Eisenstein, Maus procura representar la sombra del horror y del sufrimiento que acompañaron a la inmensa mayoría de los supervivientes del Holocausto (tanto en Europa como en Norteamérica u Oriente Medio), junto con sus hijos y familias, durante los últimos años de la década de los cuarenta y, especialmente, durante las décadas del silencio y de la "recuperación de la normalidad" de los cincuenta-sesenta y de los setenta-ochenta, respectivamente. Un grito callado se alimentó durante décadas en el corazón y en el cerebro de miles de víctimas del Holocausto, hasta que el clima internacional se volvió más empático y receptivo a su sufrimiento. Como escribe Witek, "the ostensible subject of the book, the Holocaust, es finally subordinated to the relationship between Art and Vladek as they collaborate on turning Vladek's memories into art. Maus is thus in large part about the process of its own writing", 30

Así, Maus es un ejercicio de postmemoria; ${ }^{31}$ o de transmisión intergeneracional de un trauma, de un trauma que sigue estando presente y cuyas heridas siguen abiertas. ${ }^{32}$ De esta forma, las experiencias ajenas, el recuerdo de las mismas, llegan a formar parte del acerbo y del "recuerdo" de uno mismo. Como escriben Seeberg, Levin y Lenz, "three generations have now been reaised in societies where former survivors,

\footnotetext{
${ }^{27}$ Mark H. Moss, Toward the Visualization of History: The Past As Image (Lanham: Lexington Books, 2010), 172.

${ }^{28}$ Vid. Dominick LaCapra in "Fue la noche anterior a Navidad: Maus, de Art Spiegelman", en LaCapra, Historia y memoria después de Auschwitz, 161-205. Y Andreas Huyssen, "Of Mice and Mimesis: Reading Spiegelman with Adorno", New German Critique, 81, 3 (2000): 65-82, 78.

${ }^{29}$ Escribir la historia, escribir el trauma (Buenos Aires: Nueva Visión, 2005), 105.

${ }^{30}$ Joseph Witek, Comic Books as History, 98.

31 Marianne Hirsch, Family Frames. Photography, Narrative and Postmemory (Cambridge: Harvard University Press, 1997), 22. Lo fundamental aquí es el hecho de que tales recuerdos se materializan en el presente y producen la sensación de que el pasado "pervive" en ellos.

32 Amy Hungerford, The Holocaust of Texts: Genocide, Literature, and Personification (Chicago: University of Chicago Press, 2003), 94. Sobre la relación entre los distintos planos generacionales en Maus, vid. Candida Rifkind, "Drawn from Memory: Comics Artists and Intergenerational Auto/biography", Canadian Review of American Studies, 38, 3 (2008): 399-427. Sobre la metáfora de la herida abierta en Maus, vid. Silvana Vetö, "Maus y la ética de la representación después del Holocausto. Narrativas post-traumáticas, elaboración y post-memoria", Liminales. Escritos sobre psicología y sociedad, 1, 1 (2012): 71-113, 94.
} 
perpetrators, and vistanders continued to live after 1945,33 con lo que las memorias colectivas de las víctimas tienen un papel activo en la representación del sufrimiento padecido, en la denuncia de las víctimas y en la reclamación de reconocimiento. James Young destaca el carácter vicario de los "recuerdos" de aquellas experiencias que no se han vivido directamente por los individuos pero que, sin embargo, forman parte de su memoria. ${ }^{34}$ Este es uno de los temas importantes de Maus: que los recuerdos traumáticos son historias de sufrimiento y crueldad que permancen en el presente, que quedan inconclusas y que, por tanto, no tienen final feliz. Por ello, en toda la obra, además de un intento por desentrañar el pasado, éste también irrumpe en el presente de forma imprevisible y traumática. De hecho, en varias ocasiones, es el mismo Spiegelman el que pregunta, insiste y, finalmente, obliga a su padre a actualizar su recuerdo de Auschwitz, muchas veces a través de unas entrevistas mediante las cuales fuerza a su padre a recordar experiencias que preferiría poder olvidar. Es la misma estrategia que había usado Lanzmann para su panorámica sobre la experiencia concentracionaria a partir de las entrevistas a víctimas, victimarios y colaboradores incluidas en su Shoah. Precisamente, Maus intenta dar cuenta de una experiencia típica de los supervivientes del Holocausto: la memoria del sufrimiento, que les ata al pasado y al presente, y el deseo de esperanza, que les puede permitir sobrevivir, a su vez, a la experiencia concentracionaria. Como Wiesel, Spiegelman también está entre la memoria y la esperanza. ${ }^{35}$ Y ello porque ambos sobrevivieron al Holocausto.

Sin embargo, también existen cómics sobre el testimonio de víctimas que no sobrevivieron a la Shoah. Por ejemplo, la novela gráfica El diario de Anne Frank, con guión de Ari Folman (el director de Vals con Bashir) e ilustraciones de David Polonsky y resultado de un encargo de la Fundación Ana Frank. ${ }^{36}$ Folman y Polonsky decicieron aceptar el encargo de enfrentarse a "un icono de la memoria de la barbarie nazi" y de asumir "el reto de ofrecer a los jóvenes lectores de la era digital un formato accesible para conocer la excepcional historia de la adolescente judía, fallecida en el campo de Bergen-Belsen tras ser deportada a Auschwitz", en la pequeña localidad polaca de Oświęc. ${ }^{37}$ Por otro lado, también podemos encontrar obras gráfico-textuales sobre la denuncia contemporánea de los campos de concentración y de exterminio, como el extraordinario Jan Karski. El hombre que descubrió el holocausto, de Rizzo y Bonaccorso, un cómic biográfico sobre un miembro de la resistencia polaca, Jan Karski, que escapó del gueto de Varsovia y viajó a los EE.UU. para denunciar, sin mucho resultado, lo que estaba ocurriendo en los márgenes del Tercer Reich, especialmente en relación con los "supuestamente secretos" campos de exterminio nazis. ${ }^{38}$ Pero también existen cómics que intentan representar la experiencia concentracionaria, con su variada

\footnotetext{
33 Marie Louise Seeberg, Irene Levin y Claudia Lenz, The Holocaust as Active Memory: The Past in the Present (Abingdon y New York: Routledge, 2016), 1.

${ }^{34}$ James Young, The Texture of Memory: Holocaust Memorials and Meaning (Dexter: Yale University Press, 1994), 271 y 297 y Young, At Memory's Edge. After-Images of the Holocaust in Contemporary Art and Architecture (New Haven y London: Yale University Press, 2000). Sin embargo, toda experiencia del pasado es, de por sí, vicaria. Beatriz Sarlo, Tiempo pasado. Cultura de la memoria y giro subjetivo (Buenos Aires: Siglo XXI, 2005), 129.

${ }^{35}$ Carol Ritter, Elie Wiesel: Between Memory and Hope (New York: NYU Press, 1991).

36 Ari Folman y David Polonsky, El diario de Anne Frank (Barcelona: Debolsillo, 2017).

${ }^{37}$ Vid. los testimonios de Folman en Eva Cantón, “'El diario de Ana Frank' llega al cómic”, El Periódico, 18 de septiembre de 2017 (https://www.elperiodico.com/es/ocio-y-cultura/20170918/comic-diario-anafrank-ari-folman-polonsky-6286388, 15-01-2018).

38 Marco Rizzo y Lelio Bonaccorso, Jan Karski. El hombre que descubrió el holocausto (Barcelona: Norma, 2015).
} 
y terrible fenomenología de deshumanización, violencia y horror. En el cómic USAmericano, por ejemplo, se vienen intentado representar varias dimensiones del Holocausto desde tiempos tan pioneros como la propia $2^{\mathrm{a}}$ G.M. y la inmediata postguerra. Así, existen comic strips y comic books que proporcionan representaciones de la vida en los campos de concentración y de exterminio (como la que se hace en "Master Race", de Al Feldstein y Bernard Krigstein, Impact. EC Comics, 1955) o la descripción de las cámaras de gas (en "Escape from Maidenek", de Vince Napoli, Youthful Magazines, 1952). ${ }^{39}$

Como han señalado multitud de autores, existe una interacción dialéctica permanente entre los prejuicios del historiador (en el sentido gadameriano del término: prejuicios positivos y negativos) y la forma en que la investigación le va afectando, hecho que la narración de Spiegelman muestra explícita y críticamente, al contrario que muchas monografías historiográficas académicas. Maus constituye un intento de explicar un acontecimiento del pasado, a la luz del recuerdo de la experiencia de un superviviente, mezclando los distintos puntos de vista generacionales implicados en el problema de su representación y sobre la base de los problemas que suscita en el presente. ${ }^{40}$ En este sentido, es una obra multivocal. Pero Maus, también, plantea graves problemas sobre la construcción de la identidad, ${ }^{41}$ problemas que son, además, de gran actualidad. ${ }^{42}$ Como ya he dicho, el relato explícito del cómic consiste en el esfuerzo del hijo de un superviviente para que su padre le cuente cómo fue su experiencia del Holocausto. Pero el relato implícito consiste en la dificultad de representar, con los medios de un discurso gráfico-textual, como los del cómic, determinadas experiencias límite. En este sentido, es un relato policrónico. ${ }^{43}$ Ésta es una de las características que hacen de Maus un experimento historiográfico postmoderno. ${ }^{44}$ Además, el relato enfrenta un complejo entramado de relaciones y transferencias entre los distintos personajes, entre el "acting out" del padre y el "working through" del protagonista. ${ }^{45}$ Finalmente, Maus es, también una historia íntima, una historia personal, en la que el autor está subjetivamente implicado y que le permitió enfrentar y "superar" el suicidio de su madre y la memoria traumática de su padre.

\footnotetext{
39 Vid. Markus Streb, "Early Representations of Concentration Camps in Golden Age Comic Books: Graphic narratives, American Society, and the Holocaust", Scandinavian Journal of Comic Art (SJOCA), 3, 1 (2016): 29-63.

${ }^{40}$ Carlos A. Scolari, Historietas para sobrevivientes: Cómic y cultura de masas en los años 80 (Buenos Aires: Colihue, 1999), 228.

41 Victoria A. Elmwood, "Happy, Happy Ever After": the Transformation of Trauma between the Generations in Art Spiegelman's Maus: a Survivor's Tale”, Biography, 27, 4 (2004): 693-720.

${ }^{42}$ Sobre la preocupación actual por el Holocausto, vid. Peter Novick, Judios, ¿vergüenza o victimismo?: el Holocausto en la vida americana (Madrid: Marcial Pons, 2007).

43 Sobre los distintos planos narrativos de Maus, vid. Erin McGlothlin, "No Time Like the Present: Narrative and Time in Art Spiegelman's Maus", Narrative, 11, 2 (2003): 177-198, 192.

${ }^{44}$ Aitor M. Bolaños de Miguel, "Experimentos historiográficos postmodernos", Revista de historiografía, 13, 2 (2010): 100-114.

45 Sobre el uso de estos términos psicoanalíticos para el análisis de Maus, vid. Dominick LaCapra, Representar el Holocausto, Historia, teoría y trauma (Buenos Aires: Prometeo, 2008), 219 y ss.; y, también, Janice Morris, "Of Mice and Men: Collaboration, Postmemory and Working Through in Art Spiegelman's Maus: A Survivor's Tale“, en Richard Iadonisi (ed.), Graphic History: Essays on Graphic Novels and/as History (Newcastle upon Tyne: Cambridge Scholars Publishing, 2012), 6-35.
} 
De esta manera, Maus combina, de una forma claramente postmoderna, biografía, autobiografía, etnografía ${ }^{46}$ e investigación historiográfica en un intento por desentrañar y representar un acontecimiento histórico que, además, en este caso, es un "limit event". ${ }^{47}$ Como han señalado Curthoys y McGrath, tanto la teoría como la práctica historiográfica postmoderna, como Maus, subrayan la importancia del papel, auto consciente y auto reflexivo, del historiador, entendido como el narrador de "su" (de "la") historia. ${ }^{48}$ Además de subrayar los elementos psicológicos y emocionales en todo acercamiento al pasado, especialmente a eventos traumáticos recientes como el Holocausto. Por su parte, la apuesta representativa de Spiegelman, la capacidad de circunscribir su representación a las viñetas de un cómic, describiendo y explicando diversos acontecimientos y experiencias personales, tanto del pasado como del presente, está relacionada con "una investigación cuidadosa y realmente dolorosa, así como con una exacta reconstrucción de un contexto contemporáneo". ${ }^{49}$ Por todo ello, Maus funciona a la perfección como una obra compleja e híbrida sobre la memoria, la historia y el duelo, "en el margen entre la reconstrucción histórica auto-etnográfica y el arte". 50

Maus es una representación híbrida, con una mezcla de texto e imágenes, es decir: gráfico-textual, como otros productos culturales de la misma o similar naturaleza: The Jewish Holocaust for Beginners, de Stewart Justman; We won't see Auschwitz, de Jérémie Dres; Esperaré siempre tu regreso, de Jordi Peidro (sobre la presencia de españoles en Mauthausen); ${ }^{51}$ o la novela gráfica Yossel April 19, 1943, de Joe Kubert. ${ }^{52}$ Es aquí donde se plantea una de las más importantes y arriesgadas apuestas de la obra: la interrelación entre la imagen y la palabra así como su capacidad para impactar en la memoria colectiva a través de una representación que está en consonancia con las nuevas prácticas culturales entre las generaciones más jóvenes. ${ }^{53}$ Como ha sugerido Sontag, "recordar es, cada vez más, no tanto recordar una historia sino ser capaz de evocar una imagen". 54 Y el cine, el cómic y la televisión son los medios privilegiados, junto a la fotografía, mediante los cuales los ciudadanos del siglo XX y comienzos del XXI tomamos conciencia de una realidad, evocándola audio-visualmente. De hecho, por ejemplo, las fotografías familiares son marcos mediante los que elaboramos nuestras identidades individuales y colectivas, como ha mostrado Hirsch, especialmente en situaciones dolorosas y traumáticas como el Holocausto. ${ }^{55}$

\footnotetext{
${ }^{46}$ Rosemarie Hathaway en "Reading Art Spiegelman's Maus as Postmodern Ethnography", Journal of Folklore Research 48, 3 (2011): 249-267.

47 Llüisa Faxedas, "De ratones y hombres. Maus, de Art Spiegelam”, Escritura e imagen, 6 (2010): 129$145,145$.

${ }^{48}$ Ann Curthoys y Ann McGrath, How to Write History That People Want to Read (New York: Palgrave Mcmillan, 2011), 9.

49 Dominick LaCapra, "Fue la noche anterior a Navidad", 168.

${ }^{50}$ Ibid., 205.

${ }^{51}$ Sobre Mauthausen, es interesante leer Prisionero en Mauthausen, de Javier Cosnava. Y Deportado 4443: Sus tuits ilustrados, de Ioannes Ensis y Carlos Hernández de Miguel

52 Sobre la novela gráfica judía, vid. Samantha Baskind y Ranen Omer-Sherman (eds.), The Jewish Graphic Novel: Critical Approaches (New Brunswick: Rutgers University Press, 2010) y Henry Gonshak y Montana Tech, "Beyond Maus: Other Holocaust Graphic Novels", Shofar: An Interdisciplinary Journal of Jewish Studies, 28, 1 (2009): 55-79. Gonshak y Tech estudian las diferencias y similitudes entre la obra de Spiegelman y las siguientes novelas gráficas: A Life Force, de Will Eisner; Yossel: April 19, 1943, de Joe Kubert; y Auschwitz, de Pascal Croci.

${ }^{53}$ LaCapra, "Fue la noche anterior a Navidad", 198.

54 Susan Sontag, Ante el dolor de los demás (Barcelona: Círculo de lectores, 2003), 115.

55 Marianne Hirsch, Family Frames: Photography, Narrative and Postmemory.
} 
Maus completa su juego significativo sorteando una representación realista, al estilo decimonónico, del pasado. Es decir, de una forma alegórica, dando forma animal a los personajes de su historia, en la tradición de Krazy Kat ${ }^{56}$ para subrayar la relación depredadora y de explotación que existe entre ellos. ${ }^{57}$ Así, Spiegelman representa a los judíos como ratones, a los nazis como gatos y a los polacos como cerdos. También aparecen ranas (que son los franceses) y perros (que son los americanos), formando, así, una fábula expresionista, una "amarga sátira" antropomórfica, ${ }^{58}$ que parece apuntalar algunos elementos comunes a distintas representaciones sobre el Holocausto, en una suerte de americanización del Holocausto que, por influencia, constituye, también, una suerte de crisol para una memoria transnacional de la Shoah. Sin embargo, ¿qué habría pasado si Spiegelman hubiera representado a los judíos como gatos y a los nazis como ratones? Una de las características postmodernas de esta novela gráfica es que Spiegelman toma partido por las víctimas y por su innecesario sufrimiento, denunciando claramente, además, a los victimarios. Maus no pretende ser un documental sobre el Holocausto, no ofrece imágenes realistas de las personas implicadas en la Solución Final. Pero lo que sí pretende ser es una representación fidedigna sobre la complejidad dialógica entre las víctimas y sus familiares y testigos, en general, y entre una familia superviviente y su propio hijo (Vladek y Art), en particular, entrelazando el eco de la experiencia concentracionaria con la memoria de la misma en el presente. ${ }^{59}$ En esta misma dirección, conviene mencionar el cómic The Boxer: The True Story of Holocaust Survivor Harry Haft, de Reinhard Kleist (2014).

Por cierto, estamos hablando de una estilización artística, de una deconstrucción de la propaganda nazi y de un juego alegórico que ha sido recuperado por Quentin Tarantino en el famoso discurso del coronel de las SS, Hans Landa, al comienzo de su farsa antinazi Inglourious Basterds. ${ }^{60}$ Recordemos que el término farsa hace referencia a una representación exagerada de la realidad pero que mantiene una poderosa verosimilitud. Y este aspecto tampoco es descuidado en Maus. Al contrario, la obra de Spiegelman ofrece una reconstrucción detallada (y, en la medida de nuestro conocimiento, bastante fidedigna, por lo menos en su aspecto "externo") del universo concentracionario así como del propio exterminio (al contrario que la obra de Lanzmann, que se sostiene exclusivamente sobre la palabra y el gesto de los supervivientes, sobre lo que Friedlander ha denominado un "realismo alusivo", que haría relación a un aspecto "interno" y posterior al acontecimiento), aunque esto no es lo más importante de la obra, como ha resaltado Young. ${ }^{61} \mathrm{Y}$ lo hace mostrando la crueldad de los procedimientos, la naturaleza trágica de lo ocurrido así como de la propia experiencia sufrida, el humor patibulario de una buena parte de la vida en el campo de concentración, ${ }^{62}$ las consecuencias actuales de los traumas, etc., y todo ello

\footnotetext{
${ }^{56}$ Ibid., 182 y ss.

${ }^{57}$ Hirsch, Family Frames, 27.

${ }^{58}$ Hayden White, "Historical Emplotment and the Problem of Truth", en Friedlander, Probing the Limits of Representation (Cambridge y London: Harvard University Press, 1992), 37-53, 41.

59 Vid. Douglas Wolk, Reading Comics. How Gaphic Novels Work and What They Mean (New York: DaCapo Press, 2007), 345.

60 -Vid. Thomas Doherty, “Art Spiegelman's Maus: Graphic Art and the Holocaust”, American Literature, 86, 1 (1996): 69-84.

${ }^{61}$ James A. Young, "The Arts of Jewish Memory in a Postmodern Age”, en Jorn Rüsen (ed.), Meaning and Representation in History (Nueva York: Berghahn Books, 2006), 239-254, 250.

${ }^{62}$ Un humor que, por cierto, fue usado de forma extrema en Hitler=SS, de Jean-Marie Gourio, Philippe Vuillemin y Gondot (EPCO Editions, París, 1987), una publicación gráfica que sigue estando prohibida en España.
} 
sin dejar de mostrar algunas de las características de lo carnavalesco, en el sentido amplio que le da al término Mikhail Bakhtin, y que, en todo caso, subraya el acercamiento a lo diferente, a la alteridad. Como escribió Rousset, en los campos de concentración, como en el de Buchenwald, reinaba una "bufonería trágica", un "desmesurado sentido del humor", de inspiración ubuesca (es decir, bajo inspiración de un siniestro cinismo). ${ }^{63}$

El problema más importante y espinoso que plantea Maus es cómo resolver las dificultades acerca de la interpretación de un acontecimiento que parece escaparse de las categorías interpretativas normales, como han afirmado Friedlander y Bauman. ${ }^{64}$ Para intentar relacionar el testimonio del padre, superviviente de un campo de concentración nazi, con el relato del hijo, que intenta entender y narrar dicho testimonio, ${ }^{65}$ Spiegelman recurre a lo que se conoce como la "escritura intransitiva" o "middle voice", propuesta por Roland Barthes, Jacques Derrida, Berel Lang o Hayden White, entre otros. Una voz que aproxima, casi hasta confundirlos, al narrador, a los acontecimientos que quiere representar y al propio intento textual y discursivo de representarlos. Y, sin embargo, lo hace de una manera irónica, reflexiva, auto crítica, mostrando "las costuras". En este sentido, esta aproximación disimula el hecho de que dicha confusión es artificial, como artificial es también el juego entre líneas temporales que acercan y superponen el pasado con el presente. En buena medida, como el monólogo interior, que también persigue el efecto de intentar acabar con representaciones clausurantes y autoritarias. ${ }^{66}$ Así, Maus se puede leer como un documental subjetivo (como Persépolis de Marjane Satrapi, o Palestina, de Joe Sacco), en el que lo importante no es tanto la descripción y explicación del testimonio paterno como el intento de la generación posterior por interpretar el acontecimiento de fondo: el Holocausto.

Aunque Spiegelman mezcla en su cómic distintas líneas temporales, que se cruzan en una misma página, se cuida de no superponerlas en una misma viñeta. Aunque podemos encontrar excepciones: como cuando Vladek, el padre de Spiegelman, relata cómo unas chicas fueron ahorcadas en Auschwitz mientras su hijo conduce hacia una tienda cercana para cambiar unos paquetes de comida. O como cuando Spiegelman aparece enmascarado como un ratón, en su lugar de trabajo, intentando dar forma a su experiencia como testigo del relato (o mejor dicho, del conjunto de relatos) de un superviviente, que es, además, su propio padre. En páginas anteriores, Spiegelman ya había reconocido su incapacidad para entender la experiencia relatada por su padre, de darle un sentido, por lo que reconoce la dificultad (cuando no la imposibilidad) de asignar un significado general al Holocausto: "soy incapaz de darle un sentido a mi relación con mi padre... ¿Cómo voy a dárselo a Auschwitz, al Holocausto?",67

En este sentido, LaCapra considera que White apela a la llamada "middle voice" (en el nivel discursivo, no en el gramatical) como la manera más apropiada de

\footnotetext{
${ }^{63}$ David Rousset, El universo concentracionario (Barcelona: Anthropos, 2004), 12.

${ }^{64}$ Saul Friedlander, Probing the limits of Representation, 3; Bauman, Modernidad y Holocausto (Madrid, Sequitur, 1998), 12.

65 Vid. Deborah R. Geis, Considering Maus: Approaches to Art Spiegelman's "Survivor's Tale" of the Holocaust (Tuscaloosa: University of Alabama Press, 2003).

${ }^{66}$ Vid. Verónica Tozzi, "Racionalidad y eficacia crírica en una historia multívoca", en L.E. Hoyos, Relativismo y Racionalidad (Bogotá: Unibiblos, 2005), 171.

${ }^{67}$ Art Spiegelman, Maus (Barcelona: Mondadori, 2005), 174.
} 
representar el Holocausto y de escribir sobre el trauma, tanto de supervivientes como de sus hijos, familiares y descendientes. ${ }^{68}$ El propio White ha afirmado en repetidas ocasiones que la "middle voice" es el mejor de los mecanismos para construir representaciones sobre esta clase de sucesos límite, traumáticos, y ha puesto el ejemplo de la obra de Primo Levi así como el de Maus, ya que hacen de la representación del Holocausto algo intransitivo y autorreferencial.

Finalmente, como han afirmado varios comentaristas, una de las conquistas de Maus es que consigue señalar el horror que supuso el Holocausto sin llegar a estetizarlo. Y, además, consigue que el lector de comienzos del siglo XXI empatice con el sufrimiento padecido por las víctimas directas del Holocausto así como por sus hijos y familiares, reconociendo su condición de víctimas, rehabilitando sus memorias y transformándoles, finalmente, en "vencedores en la derrota". Los experimentos postmodernos, como Maus, fomentan una "ética de la mirada" que, tal y como han escrito Picart y Frank, permite el desarrollo de un público crítico e informado, para que ninguna representación del Holocausto se deslice hacia el voyeurismo, hacia el morbo inconsciente, hacia la empatía por el victimario pero, tampoco, hacia ninguna rigidez binaria o hacia la demonización pura y dura. ${ }^{69}$ Los experimentos historiográficos postmodernos intentan implicar al público, reclamando su participación y sacándole de la posición de meros observadores. Eso es lo que ocurre también, en La hija de Mendel. Una memoria, novela gráfica elaborada por Martin Lemelman a partir de las grabaciones que realizó a su madre, Gusta, en 1989, en las que recordaba sus experiencias en Polonia y sus intentos de supervivencia frente a la ocupación nazi.

Para concluir, podemos estar de acuerdo con el propio White cuando afirma que Maus no es una representación historiográfica convencional del Holocausto pero sí es "una representación de sucesos reales del pasado o, al menos, de sucesos que se representan como habiendo realmente ocurrido", que es, exactamente, lo que hace cualquier libro de texto histórico. ${ }^{70}$ De hecho, es una representación estilizada, sofisticada y alegórica pero sin caer en estetización, banalización o melodramatización alguna, como se han quejado autores como Friedlander o Lanzmann respecto de otras representaciones del Holocausto. Hay que tener en cuenta que Maus es una representación historiográfica que nació en el contexto del cómic underground (fue publicado por entregas en la revista $R a w$, entre 1977 y mediados de los ochenta), que traspasó los límites temáticos y estilísticos del medio en que fue realizado y que ha conseguido popularizar las "novelas gráficas" e, incluso, ganar el Premio Pulitzer, que concede la Universidad de Columbia. ${ }^{71}$ Finalmente, White también considera que Maus se las arregla para plantear la inmensa mayoría de cuestiones espinosas relacionadas con

\footnotetext{
${ }^{68}$ Escribir la historia, escribir el trauma (Buenos Aires: Nueva Visión, 2005), 49.

${ }^{69}$ Caroline Joan Picart y David A. Frank, Frames of Evil: The Holocaust as Horror in American Film (Carbondale: Souther Illinois University Press, 2006), 125.

${ }^{70}$ Hayden White, "El entramado histórico y el problema de la verdad", en Saul Friedlander, En torno a los límites d ela representación (Buenos Aires: Universidad Nacional de Quilmes Editorial, 2007), 75.

${ }^{71}$ También fue nominado al National Book Critics Circle Award en la categoría de mejor biografía. Una cuestión que este artículo no estudia, pero que podría ser interesante analizar, es la cuestión de si el comic undergound USAmericano, por ejemplo, comparte una serie de características discursivas con Maus a la hora de intentar representar el Holocausto y sus diversas aporías.
} 
la naturaleza y los límites de la representación historiográfica, especialmente de "acontecimientos modernistas" límite como el Holocausto ${ }^{72}$.

\section{Conclusiones infelices}

Tal y como he intentado sugerir en este texto, la representación del Holocausto no solamente es posible, aunque extremadamente problemática, sino también necesaria. Y ello pese a que, como escribe LaCapra, el Holocausto ha sido tanto reprimido como 'canonizado' en las últimas décadas. El objetivo de este texto es señalar la importancia de formas auto-reflexivas y auto-críticas de representar el Holocausto con la intención de "cepillar la historia a contrapelo", como quería Walter Benjamin. A estas formas auto-reflexivas y auto-críticas las denomino "postmodernas", aunque tienen otras características que he intentado señalar en este artículo.

Mi intención ha sido subrayar que la representación del pasado puede ser más fructífera si se complementa con las técnicas estudiadas en este artículo y no sola y exclusivamente con las técnicas de la historiografía tradicional. De esta forma, se puede intentar dar cuenta de las dimensiones fácticas y cronológicas de un fenómeno histórico pero, también, de sus múltiples significados y experiencias subjetivas. Es decir, se puede intentar representar tanto lo que ocurrió (lo que puede ser descrito y explicado mediante el estudio de las fuentes disponibles) como la experiencia de los individuos implicados (lo que puede ser representado teniendo en cuenta el testimonio de las víctimas, de los supervivientes e, incluso, de los victimarios). Como ha escrito White, "conjuring up of the past requires art as well as information". ${ }^{73}$ Novelas gráficas como Maus, The Searcher o Judenhass, y películas como Noche y niebla, The Sorrow and the Pity y Shoah (entre otras), han estimulado un efecto significativo en el comportamiento de las audiencias de finales del siglo XX: un cambio de interés a favor del testimonio, tanto documental como personal, en lugar de la historiografía tradicional. En tiempos más recientes, estas obras, y otras parecidas, han llevado a públicos más amplios y más jóvenes la crudeza de una época y de un acontecimiento, el Holocausto, que todavía sigue resonando en nuestras sociedades postmodernas y postindustriales.

En el fondo, lo que plantean la teoría y la práctica historiográfica postmoderna es que cualquier representación historiográfica no es más que un conjunto de descripciones parciales, de explicaciones aproximadas y de interpretaciones plausibles: eso es lo que llamamos "historia". Un conjunto de representaciones no clausurantes, no cerradas, no definitivas, sin final. Y mucho menos, sin final feliz. La "voz media" que propone White, por ejemplo, y que encarna algo así como la differénce derridiana (tal y como nos ha recordado LaCapra), ${ }^{74}$ nos puede ayudar a conjugar las dimensiones fácticas de nuestras representaciones del pasado junto con las dimensiones emocionales, empáticas, experienciales y éticas. La memoria del sufrimiento de las víctimas, por

\footnotetext{
${ }^{72}$ En este artículo, no voy a entrar en las cuestiones del inglés usado por Spiegelman en la edición original, un inglés ciertamente idiosincrásico y con claras influencias yídish, que no todas las traducciones al castellano han conseguido hacer justicia.

73 Hayden White, "Introduction: Historical Fiction, Fictional History, and Historical Reality", Rethinking History, 9, 2-3 (2005), 147-157, 149.

${ }^{74}$ Escribir la historia, escribir el trauma, 44.
} 
tanto, complementa los intentos de objetivación de la historiografía convencional, realizada en la académica o fuera de ella.

Por otro lado, una idea que también he intentado destacar en este texto es que nuestras representaciones sobre dicho acontecimiento no pueden "terminar bien". De esta forma, si se quiere ser respetuoso con el amplio conjunto de significados que engloba el espectro metafórico del término Holocausto, es conveniente insistir en que los efectos negativos y traumáticos del fenómeno siguen vigentes en nuestro presente. No hay final feliz cuando hablamos del Holocausto. La "Solución final" no puede tener un "final feliz". No hay lugar para la neutralidad y para la imparcialidad alrededor de un acontecimiento histórico con tantas víctimas y con tanto sufrimiento, tanto en el pasado como en el presente. Además, un final feliz no ayuda a enfrentar los problemas del pasado, los traumas del presente y los proyectos vitales frustrados de un futuro amputado. Un final feliz nos anestesia respecto del sufrimiento pasado. Y, lo que es peor, nos reconforta respecto de las resonancias de ese sufrimiento en el presente. Como ha explicado Rosenstone, el cine mainstream sobre el Holocausto suele contar una historia cronológicamente narrativa, con su comienzo, su nudo y su desenlace. Asimismo, la mayoría de las películas sobre el Holocausto se centran en la representación de las barbaries nazis, de la violencia para con sus víctimas. Y, por último, suelen incorporar un mensaje moral maniqueísta y suelen producir en el espectador algún tipo de sentimiento edificante. "Even if the subject matter is as bleak as the horrors of the Holocaust, the message is that things have gotten or are getting better" ${ }^{75}$ porque es mucho más fácil representar la violencia que el sufrimiento. En este artículo, he intentado demostrar que esta posición no hace justicia a la magnitud del Holocausto ni al sufrimiento vivido por las víctimas.

Lo que parece indudable es que "hay una relatividad inexpugnable en toda representación de los fenómenos históricos". ${ }^{76}$ Esto es un hecho que parece indiscutible. Sin embargo, la mayoría de las representaciones historiográficas afirman representar "lo que verdaderamente ocurrió" (aunque de manera provisional, condicionadas a la aparición de nuevas fuentes y testimonios). Aunque "lo que verdaderamente ocurrió", por supuesto, es que una serie concreta de victimarios produjeron dolor y sufrimiento a un número descomunal de víctimas. Pues bien, como hemos visto, para enfrentar los problemas retóricos, políticos y estéticos que plantea cualquier intento de representación historiográfica (y, más en concreto, cualquier intento de representar el Holocausto), Spiegelman recurre a un artificio que consiste en representar el relato del Holocausto enmarcado en una estrategia metaficcional acerca de cómo podría ser contado dicho relato. De esta manera, la narración de los hechos vividos por el padre del narrador se superponen al relato de cómo éste entrevista años después a su padre en busca de una explicación que le permita construir una representación. Es decir, la representación se vuelve auto-reflexiva y auto-critica. Esta es la dinámica representacional que Spiegelman hace explícita y que conforma un andamiaje performativo que los historiadores también han usado pero han tendido a ocultar tras múltiples convenciones retórico-académicas. Esta dinámica no esconde, además, el compromiso político de Spiegelman frente al Holocausto. Por eso, tanto Maus como Noche y niebla, por ejemplo, tienen lo que Alan Moore ha llamado una "resonancia emotiva", 77 lo que aleja

\footnotetext{
${ }^{75}$ Robert A. Rosenstone, History on Film / Film on History (Harlow: Pearson, 2012), 53.

${ }^{76}$ White, El texto histórico como artefacto literario (Barcelona: Paidós: 2003), 189.

77 Declaraciones del propio Alan Moore al comienzo de Dez Vylenz, The Mindscape of Alan Moore, película documental de 2005.
} 
a estos experimentos postmodernos de la supuesta neutralidad científica y política de buena parte de la historiografía profesional. Esta es una de las características principales de la historiografía postmoderna: la explicitación del autor, de su punto de vista, tanto de su visión política como de sus objetivos y limitaciones historiográficas, lo que estimula la delimitación de la responsabilidad que, como intelectual, supone representar un acontecimiento del pasado.

Al mismo tiempo, otra de las características de la historiografía postmoderna es la implicación subjetiva, emocional y personal del autor respecto de lo representado, como en el caso de Maus. Dicha implicación desarrolla un punto de vista ideológico sobre la base de un juicio de valor, lo cual estimula la respuesta moral y emocional del público, que puede desarrollar una afinidad moral hacia las víctimas y una antipatía ante los hechos y los argumentos de los victimarios (no como en otras películas más convencionales, en las que se puede producir, por parte del espectador, un acercamiento a la figura del nazi cruel, representado como un "monstruo", lo que acerca su visionado a una película de terror).

Más allá de la representación científica, aséptica, moralmente amable y desmovilizadora, buena parte de la historiografía, especialmente de la postmoderna, se levanta sobre un sentimiento de "vergüenza" ante el Holocausto, ${ }^{78}$ lo que define su compromiso político. "No olvidar jamás" y "nunca más" (Zakhor) van de la mano en este compromiso. No puede haber un final feliz en las representaciones postmodernas del Holocausto, porque está en juego nuestra solidaridad con el daño sufrido por las víctimas, nuestra capacidad de reconocer el sufrimiento de los supervivientes y nuestra responsabilidad en evitar acontecimientos similares. El final de Maus muestra esta naturaleza pesimista y desdichada de la historia que relata, en contraposición a los desenlaces de otras representaciones más difundidas sobre el Holocausto, como La lista de Schindler o La vida es bella, por ejemplo. Maus revela que la herida sigue abierta y que el Holocausto sigue siendo una metáfora poderosa para reflexionar sobre el mal y sobre sus consecuencias políticas, sociales y personales. No solamente respecto del pasado sino, también, respecto del presente y del futuro.

Una última conclusión es que los intentos de varios supervivientes del Holocausto por dar testimonio (tanto en el ensayo como en la literatura, tanto en la investigación histórica como en la poesía), se han visto complementados y contrastados con otras formas de representación de las experiencias traumáticas del pasado asociadas a este cruel y doloroso acontecimiento. Esta es una de las cuestiones importantes que plantea la obra de LaCapra, de Rosenstone, de Friedlander, de White y de otros autores; que plantea también el documental de Resnais y que, para terminar, ejemplifica de forma colosal el trabajo de Spiegelman. De esta forma, Spiegelman concuerda con White en que el Holocausto es un fenómeno histórico igual de incomprensible que cualquier otro acontecimiento: es decir, es representable pero a costa de aceptar su inestabilidad final, tanto fáctica como significativa. ${ }^{79}$ Esta explicitación radical del problema de la representación historiográfica es la base sobre la que se han levantado varios experimentos historiográficos postmodernos, especialmente Maus.

\footnotetext{
${ }^{78}$ Zygmunt Bauman, Modernidad y Holocausto, 237.

${ }^{79}$ Spiegelman, Maus, 231 y ss.
} 


\section{Bibliografía}

Babic, Annesa Ann (ed.), Comics as History. Comics as Literature: Roles of the Comic Book in Scholarship, Society, and Entertainment (Madison: Fairleigh Dickinson University Press, 2014).

Bauman, Zygmunt, Modernidad y Holocausto (Madrid: Sequitur, 1998).

Berenguel Aguilera, Ignacia, "Las TIC's y las viñetas. Una propuesta didáctica sobre los totalitarismos a través del cómic Maus". Espiral. Cuadernos del profesorado, 8 (2011): 42-57.

Bolaños de Miguel, Aitor, "Experimentos historiográficos postmodernos", Revista de historiografía, 13, 2 (2010): 100-114.

Caruth, Cathy, Trauma: Explorations in Memory (Baltimore: The Johns Hopkins University Press, 1995).

Chapman, Jane; Dan, Ellin y Sherif, Adam, Comics, the Holocaust and Hiroshima (Basingstoke y New York: Palgrave, 2015).

Chute, Hillary, ""The Shadow of a Past Time": History and Graphic Representation in Maus", Twentieth-Century Literature, 52, 2 (2006): 199-230.

Confino, Alon, "Narrative Form and Historical Sensation: On Saul Friedlander's The Years of Extermination", History and Theory 48, 3 (2009): 199-219.

Curthoys, Ann y McGrath, Ann, How to Write History That People Want to Read (New York: Palgrave Mcmillan, 2011).

Elmwood, Victoria, "Happy, Happy Ever After": the Transformation of Trauma between the Generations in Art Spiegelman's Maus: a Survivor's Tale”, Biography, 27, 4 (2004): 693-720.

Faxedas, Llüisa, "De ratones y hombres. Maus, de Art Spiegelam", Escritura e imagen, 6 (2010): 129-145.

Friedlander, Saul, Probing the Limits of Representation (Cambridge y London: Harvard University Press, 1992).

Hirsch, Marianne, Family Frames. Photography, Narrative and Postmemory (Cambridge: Harvard University Press, 1997).

Hungerford, Amy, The Holocaust of Texts: Genocide, Literature, and Personification (Chicago: University of Chicago Press, 2003).

Huyssen, Andreas, Después de la Gran División. Modernismo, cultura de masas y posmodernismo (Buenos Aires: Adriana Hidalgo, 2002). 
Iadonisi, Richard (ed.), Graphic History: Essays on Graphic Novels and/as History (Newcastle upon Tyne: Cambridge Scholars Publishing, 2012).

Das, Veena; Kleinam, Arthur y Lock, Margaret, Social Suffering (Berkeley y London: University of California Press, 1997).

Kukkonen, Karin, Studying Comics and Graphic Novels (Chichester: John Wiley \& Sons, 2013).

LaCapra, Dominick, Escribir la historia, escribir el trauma (Buenos Aires: Nueva Visión, 2005).

LaCapra, Dominick, Historia y memoria después de Auschwitz (Buenos Aires: Prometeo, 2008).

LaCapra, Dominick, Representar el Holocausto, Historia, teoría y trauma (Buenos Aires: Prometeo, 2008).

Landsberg, Alison, Prosthetic Memory: The Transformation of American Remembrance in the Age of Mass Culture (New York: Columbia University Press, 2004).

Lang, Berel, The Future of the Holocaust: Between History and Memory (Ithaca: Cornell University Press, 1999).

Moss, Mark, Toward the Visualization of History: The Past As Image (Lanham: Lexington Books, 2010).

Novick, Peter, Judíos, ¿vergüenza o victimismo?: el Holocausto en la vida americana (Madrid: Marcial Pons, 2007).

Frank, David A.; Picart, Caroline Joan, Frames of Evil: The Holocaust as Horror in American Film (Carbondale: Souther Illinois University Press, 2006).

Resnik, Julia, "Sites of memory' of the Holocaust: shaping national memory in the education system in Israel", Nations and Nationalism, 9, 2 (2003): 293-313.

Rosenstone, Robert, "La historia en imágenes/la historia en palabras: reflexiones sobre la posibilidad real de llevar la historia a la pantalla”, Istor, V, 20 (2005): 91-108, 93.

Rosenstone, Robert, History on Film / Film on History (Harlow: Pearson, 2012).

Rousset, David, El universo concentracionario (Barcelona: Anthropos, 2004).

Scolari, Carlos, Historietas para sobrevivientes: Cómic y cultura de masas en los años 80 (Buenos Aires: Colihue, 1999).

Lenz, Claudia; Levin, Irene y Seeberg, Marie Louise; The Holocaust as Active Memory: The Past in the Present (Abingdon y New York: Routledge, 2016).

Sontag, Susan, Ante el dolor de los demás (Barcelona: Círculo de lectores, 2003). 
Spiegelman, Art, Maus (Barcelona: Mondadori, 2005).

Vetö, Silvana, "El Holocausto como acontecimiento traumático. Acerca de la incorporación del concepto freudiano de trauma en la historiografía del Holocausto", Revista de Psicología de la Universidad de Chile, 20, 1 (2011).

White, Hayden, El texto histórico como artefacto literario (Barcelona: Paidós, 2003).

Witek, Joseph, Art Spiegelman: Conversations (Mississippi: The University Press of Mississippi, 2007).

Witek, Joseph, Comic Books as History. The Narrative of Jack Jackson, Art Spiegelman, and Harvey Pekar (Jackson: University Press Of Mississippi, 1989).

Wolk, Douglas, Reading Comics. How Gaphic Novels Work and What They Mean (New York: DaCapo Press, 2007).

Yerushalmi, Yosef, Zajor: La Historia Judía y la Memoria Judía (Barcelona: Anthropos, 2006).

Young, James, The Texture of Memory: Holocaust Memorials and Meaning (Dexter: Yale University Press, 1994).

Young, James, "The Arts of Jewish Memory in a Postmodern Age", en Jorn Rüsen (ed.), Meaning and Representation in History (Nueva York: Berghahn Books, 2006), 239-254.

Zagajewski, Adam, Solidaridad y soledad (Acantilado: Barcelona, 2010).

\section{Perfil Académico}

Aitor Bolaños de Miguel es doctor en Filosofía Política y Moral por la Universidad Nacional de Educación a Distancia (UNED), y está acreditado por la ANECA como profesor de Legislación Educativa y de Ciencias Políticas de la Universidad Internacional de La Rioja (UNIR).

\section{Academic Profile}

Aitor Bolaños de Miguel has his PhD in Political and Moral Philosophy in the National University of Distance Education (Spain), and has been accredited by the ANECA as professor of Educational Law and Political Sciences of the International University of La Rioja (Spain). 
Fecha de recepción: 27 de abril de 2019.

Fecha de aceptación: 9 de diciembre de 2019.

Publicación: 31 de diciembre de 2019.

Para citar este artículo: Aitor Bolaños de Miguel, "Las representaciones historiográficas postmodernas: Maus y la novela gráfica sobre el Holocausto", Historiografías, 18 (julio-diciembre, 2019): pp. 55-75. 